\title{
Screening of Major Chemical Reactions in In-Situ Combustion Process for Bitumen Production from Oil Sands Reservoirs
}

\author{
Yuta Yoshioka $^{1}$, Kyuro Sasaki ${ }^{2}$, Koichi Takatsu ${ }^{1}$, Yuichi Sugai ${ }^{2}$ \\ ${ }^{I}$ Graduate School of Engineering, Kyushu University, Fukuoka 819-0395, Japan \\ ${ }^{2}$ Department of Earth Resources Engineering, Fukuoka 819-0395, Kyushu University, Japan
}

*Corresponding Author: Kyuro Sasaki, Department of Earth Resources Engineering, Faculty of Engineering, Kyushu University, Japan

\begin{abstract}
In this study, screening of major chemical reactions used for numerical simulations on in-situ combustion (ISC) process has been investigated to produce bitumen from oil sands reservoir. Bitumen productions from oil sands reservoirs have been successfully carried out using thermal method, such as Steam Assisted Gravity Drainage (SAGD), but operation cost including water treatment has been a big issue to continue the bitumen production. ISC has been expected to provide high recovery, low cost and saving water. However, combustion chemical reactions and their kinetic parameters for bitumen have not been completely fixed. Some numerical simulations on the combustion tube experiments with Athabasca bitumen were conducted to construct the chemical reactions. But, screening to pick up major chemical reactions is necessary to carry out a field size reservoir simulation by reducing of CPU processing time with less number of the chemical reactions. In this study, it was confirmed that the model presented Yang and Gates (2009) could simulate the experimental results of combustion tube test better than other models. Three major reactions, defined as low temperature oxidation and high temperature oxidation (LTO and HTO), were screened based on numerical simulations by extracting a reaction one by one from the model consists eight reactions. The field scale $3 D$ numerical simulation on THAI (Toe-to-Heel Air Injection) process, an expected ISC technology to produce bitumen, has been carried out successfully for a typical oil sands reservoir by using the three reactions. Furthermore, the comparisons of numerical simulation results have been conducted between THAI and SAGD methods.
\end{abstract}

Keywords: In-Situ Combustion, Numerical Simulation, Screening, Chemical Reactions, Bitumen, Oil Sands

\section{INTRODUCTION}

The major strategy of bitumen production from oil-sands reservoirs had been changed dramatically to Steam Assisted Gravity Drainage (SAGD) method proposed by Butler and Stephens (1984) ${ }^{[1]}$ with higher recovery ratio from steam flooding methods or Cyclic Steam Injection method (CSS). It was proven that short distance and slow drainage achieved by using horizontal wells are important concepts for heavy oil production to avoid uncertainties existing in flooding processes (Sasaki et al., $2001)^{[2]}$. The slow drainage process also contributed to develop numerical simulation models to carry F/S of SAGD projects with high reproducibility. However, bitumen production by SAGD method is now facing some difficulties that are high operating cost, especially natural gas cost to generate steam and water recycling cost, $\mathrm{CO}_{2}$ emissions and environmental limitations of surface water.

In-situ combustion (ISC) or fire flooding process is one of thermal production methods, and it has a possibility to reduce the production cost due to the process without steam and water recycling. It has long developing history and is still expected to have some advantages on high recovery, saving energy and less water required for oil production, while some of the oil in place is consumed to provide heat. It is also interested in hydrogen generation by ISC process from an oil sands reservoir (Kapadia et al., 2011) ${ }^{[3]}$.

However, it has been reported that just four ISC projects have been carried out in the world (Turta et al., 2007) ${ }^{[4]}$. The reason of small number of projects tried is because the flooding process moving with combustion front and oil bank in the reservoir includes some uncertainties. Furthermore, it is also difficult to control oil production rates than that of steam injection method due to the complicated 


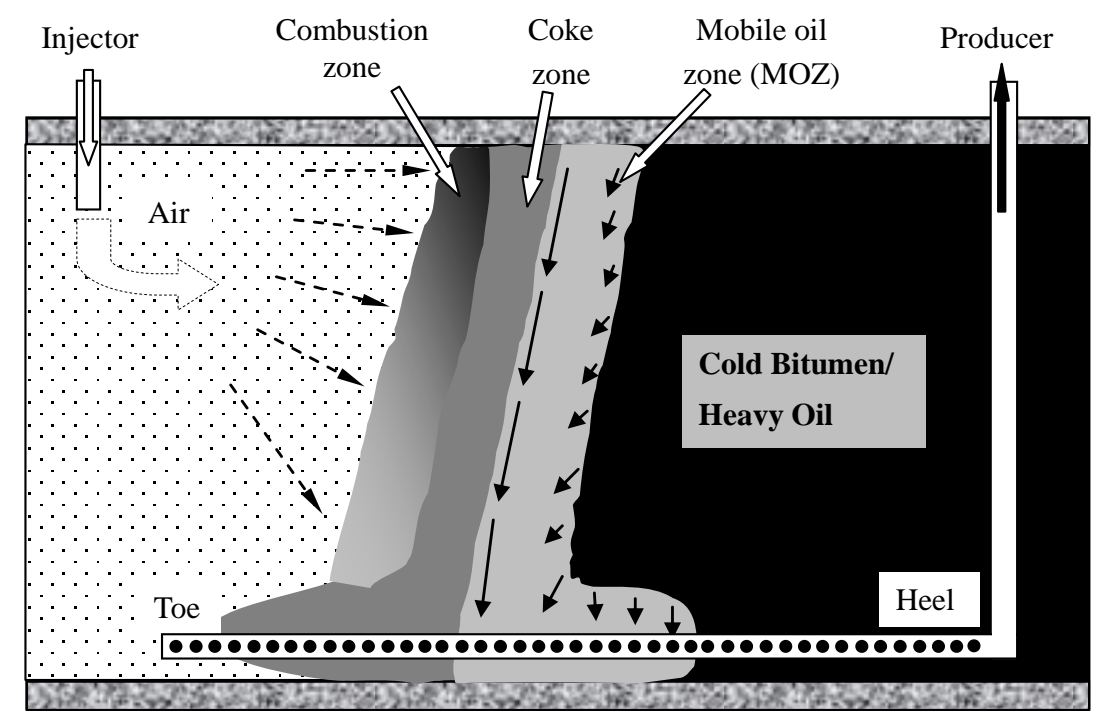

Figure1. THAI process (Xia et al., 2003) ${ }^{[6]}$

combustion chemical reactions. When ISC is applied for field productions, combustion front propagation may be difficult to control due to insufficient information on reservoir condition. In addition, kinetic parameters to express bitumen reactions are not completely investigated because related chemical reactions are complicated in different temperature ranges. As a result, ISC process has not yet achieved a commercial bitumen recovery (Yang and Gates, 2009) ${ }^{[5]}$.

The Toe-to-Heel Air Injection (THAI) method proposed by Pfefferle (2009) ${ }^{[6]}$, one of ISC methods, has a potential to produce bitumen economically, because THAI method using a horizontal producer that can control combustion front with short distance gravity drainage (Xia et al., 2003) ${ }^{[7]}$. Developing of practical numerical simulation models is required for THAI process as same as SAGD method. Its operation scheme, because THAI process still includes the complicate combustion reactions in the reservoir including heterogeneities and uncertainties.

The combustion tube tests were conducted by ISC Research Group, University of Calgary to develop ISC characteristics in the reservoir (Belgrave et al., 1993) ${ }^{[8]}$. In this study, screening of chemical reactions based on history matching simulation with CMG STARS ${ }^{\mathrm{TM}}$ was carried out to the experimental results of the tube combustion test. The three chemical reaction models proposed by Kapadia et al. (2011) ${ }^{[3]}$, Yang and Gates (2009) ${ }^{[5]}$ and Belgrave et al. (1993) ${ }^{[8]}$ have been investigated to construct a numerical simulation model on ISC. When the full chemical reactions are installed in simulations for field scale reservoir model consisting large number of grid blocks, numerical simulations may not reach convergences or need long calculation processing time. Thus, to get a reasonable numerical solution of ISC process in practical processing time, screening of chemical reactions is very effective for the field scale numerical simulations. In this study, major ISC chemical reactions for bitumen production have been selected with extracting a reaction one by one based on the simulations of the combustion tube experiment. In addition, the numerical model using the screened chemical reactions has been scaled up to the field scale in order to investigate Toe-to-Heel Air Injection (THAI) method that is one of ISC technologies as shown in Figure 1. Furthermore, the comparisons were conducted between numerical simulation results of THAI process and ones using two steam injection methods.

\section{Chemical Reactions Related in-Situ Combustion}

The numerical model consists from eight reactions proposed by Yang and Gates (2009) ${ }^{[5]}$ (herein after referred as the Y-G model) are as follows;

a) Thermal Cracking Reactions

Maltenes $\rightarrow 0.372164$ Asphaltenes

Asphaltenes $\rightarrow$ 83.23 Coke

Asphaltenes $\rightarrow 25.2962$ Gas 
b) Low Temperature Oxidation (LTO) Reactions

Maltenes $+3.43 \mathrm{O}_{2} \rightarrow 0.4726$ Asphaltenes

Asphaltenes $+7.51275 \mathrm{O}_{2} \rightarrow 101.539$ Coke

c) High Temperature Oxidation (HTO) Reaction

Coke $+1.232 \mathrm{O}_{2} \rightarrow 0.8995 \mathrm{CO}_{2}+0.1 \mathrm{CO}+0.564 \mathrm{H}_{2} \mathrm{O}$

d) Gas Phase Combustion Reactions

$$
\begin{aligned}
& \mathrm{CH}_{4}+2 \mathrm{O}_{2} \rightarrow \mathrm{CO}_{2}+2 \mathrm{H}_{2} \mathrm{O} \\
& \mathrm{Gas}+2 \mathrm{O}_{2} \rightarrow 0.9695 \mathrm{CO}+\mathrm{CO}_{2}+2 \mathrm{H}_{2} \mathrm{O}
\end{aligned}
$$

In this study, those reactions are also used for the simulations in which maltenes, asphaltenes and coke are defined as pseudo-components of bitumen.

\section{Numerical Simulation of Combustion Tube TeST}

The ISC Research Group, University of Calgary carried out the combustion tube experiment using bitumen extracted from Athabasca oil sands (Belgrave et al. ${ }^{[8]}$; Yang and Gates ${ }^{[5]}$; Yang et al. ${ }^{[10]}$ ). The experiment was done by injecting enriched air from the tube top under the pressure of 4,100 $\mathrm{kPa}$. The bitumen was ignited by heating to $400^{\circ} \mathrm{C}$, and heated oil was produced from the tube bottom.

As the first step of our study, the results of combustion tube tests were simulated numerically by CMG STARS ${ }^{\text {TM }}$ with three chemical models proposed by Belgrave et al. ${ }^{[8]}$, Yang and Gates ${ }^{[5]}$ and Kapadia et al. ${ }^{[3]}$. As shown in Figure 2, the grid-block models was used for present numerical simulations to carry history-matching to the experimental results by the combustion tube of $1.83 \mathrm{~m}$ in height reported by Belgrave et al. ${ }^{[8]}$, Yang and Gates ${ }^{[5]}$ and Greeves(2011) ${ }^{[9]}$. Table 1 shows reservoir and well operating parameters and initial conditions. The 1D model consists 200 blocks of $9.15 \mathrm{~mm}$ in vertical direction just arranged in $z$-direction to simulate one dimensional temperature profile in the tube, and 3D and 3D-tube models consider the temperature distribution in radial direction in the tube using with 4 grids. Furthermore, the 3D-tube model including the center cylindrical zone with less permeability of $80 \%$ of other models was used to enhance bitumen drainage flow and gas flow to consider the combustion tube condition.
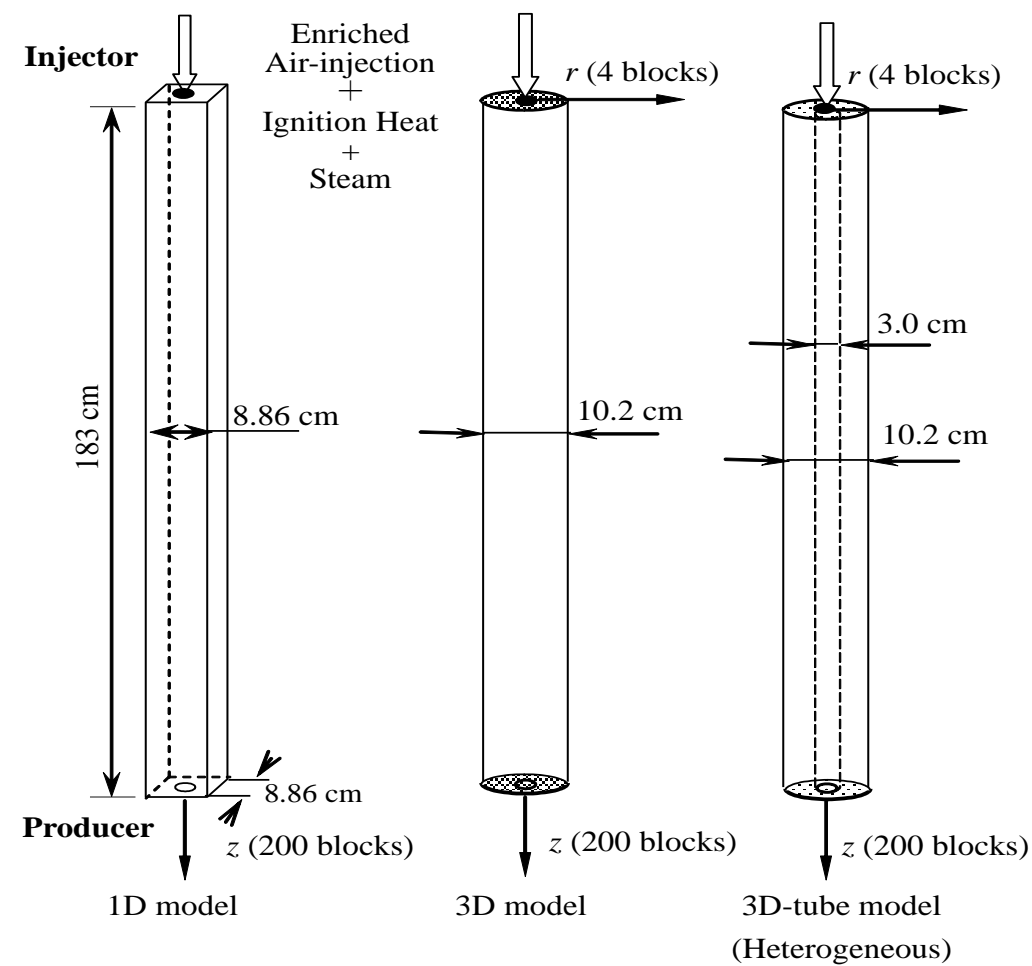

Figure2. $1 D$ and $3 D$ numerical simulation models 
Screening of Major Chemical Reactions in In-Situ Combustion Process for Bitumen Production from Oil Sands Reservoirs

Table1. Simulation parameters for tube experiment

\begin{tabular}{|c|c|}
\hline Initial Temperature $\left({ }^{\circ} \mathrm{C}\right)$ & 90 \\
\hline Initial Pressure $(\mathrm{kPa})$ & 4100 \\
\hline Porosity & 0.412 \\
\hline Permeability (md) & 11300 \\
\hline Initial Water Saturation & 0.12 \\
\hline Initial Oil Saturation & 0.70 \\
\hline Initial Gas Saturation $\left(\mathrm{CH}_{4}\right.$ mole fraction; 1$)$ & 0.18 \\
\hline Bitumen mole fraction (Maltenes) & 0.915 \\
\hline Bitumen mole fraction (Asphaltenes) & 0.085 \\
\hline
\end{tabular}

Ref. Yang and Gates (2009)

\subsection{Comparison of Block Modeling for Combustion Tube Test}

Figures 3 and 4 show comparisons of numerical simulation results of temperature distribution in the tube and temperature profiles in $z$ direction at 7.92 hours from start of ignition using $1 \mathrm{D}$ and 3D block models with the chemical model presented by Yang and Gates ${ }^{[5]}$. The differences between three models are not so large, because the combustion tube test was basically carried out to investigate 1dimensional flame-propagation by thermal insulating in radial direction. Thus, the simulation results discussed after this section were ones by the 3D block model.

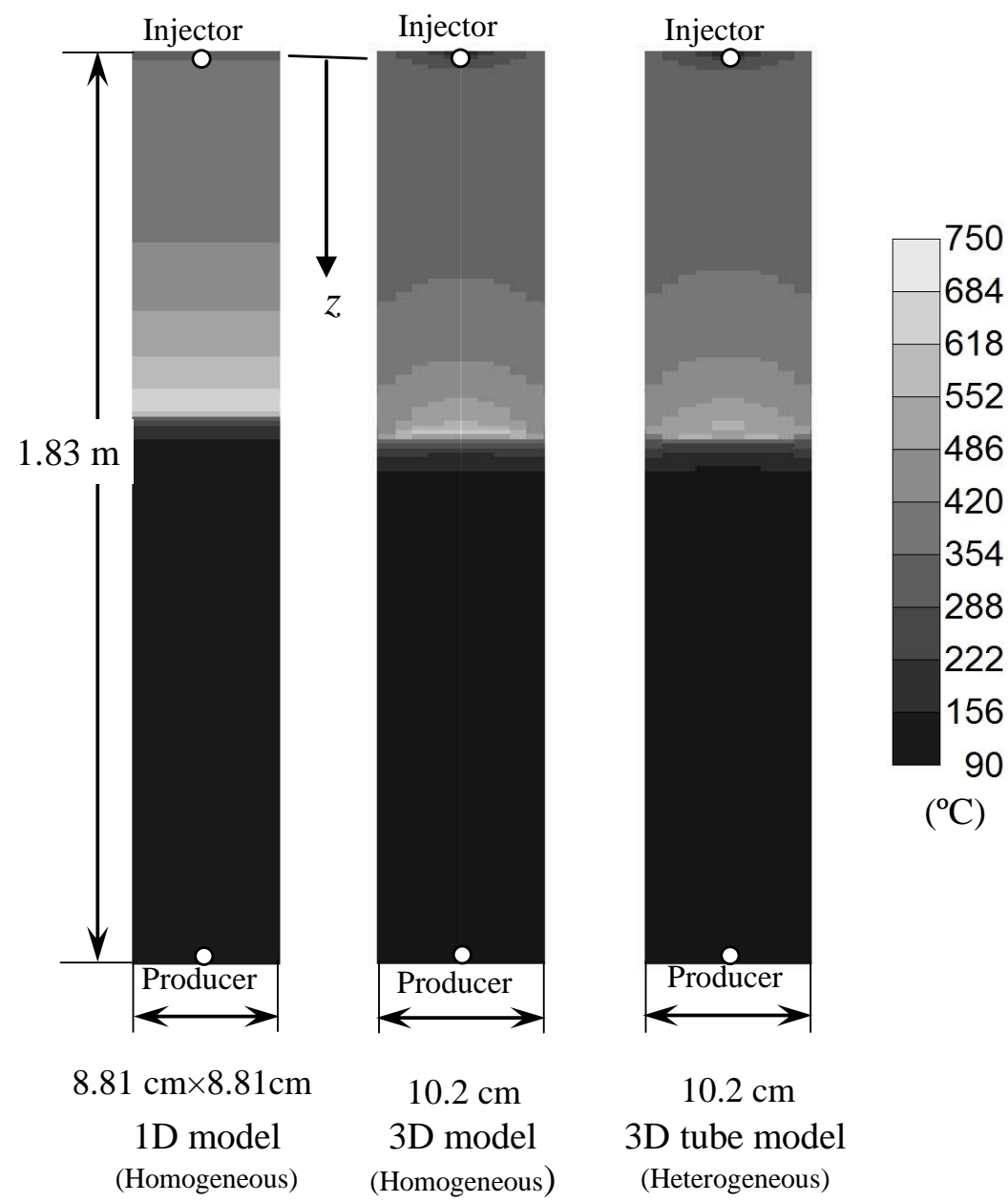

Figure3. Comparison of simulated temperature distributions in the tube at 7.92 hours from ignition by $1 D$ and $3 D$ numerical block models 
Screening of Major Chemical Reactions in In-Situ Combustion Process for Bitumen Production from Oil Sands Reservoirs

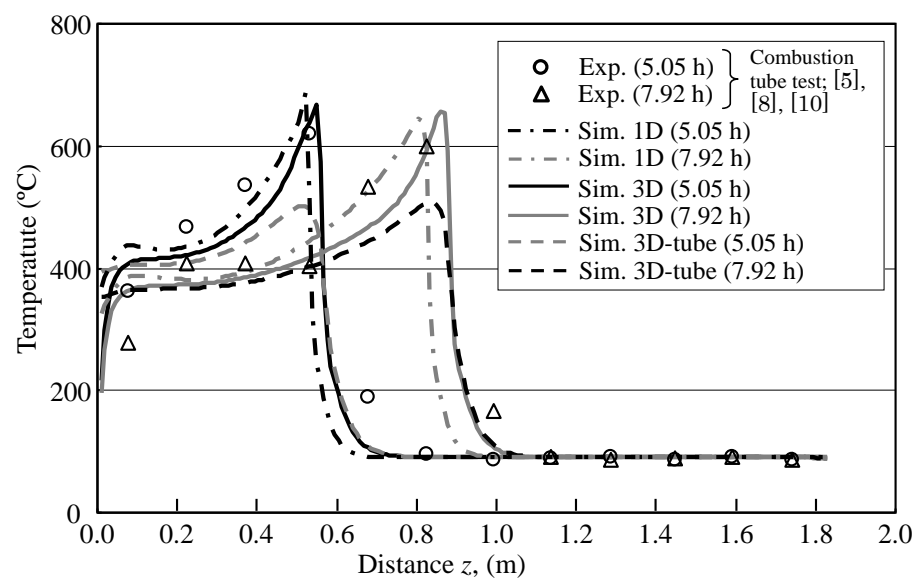

Figure4. Comparisons of numerical simulation results of temperature profile at 7.92 hours from start of ignition by $1 D$ and $3 D$ models using Yang and Gates model

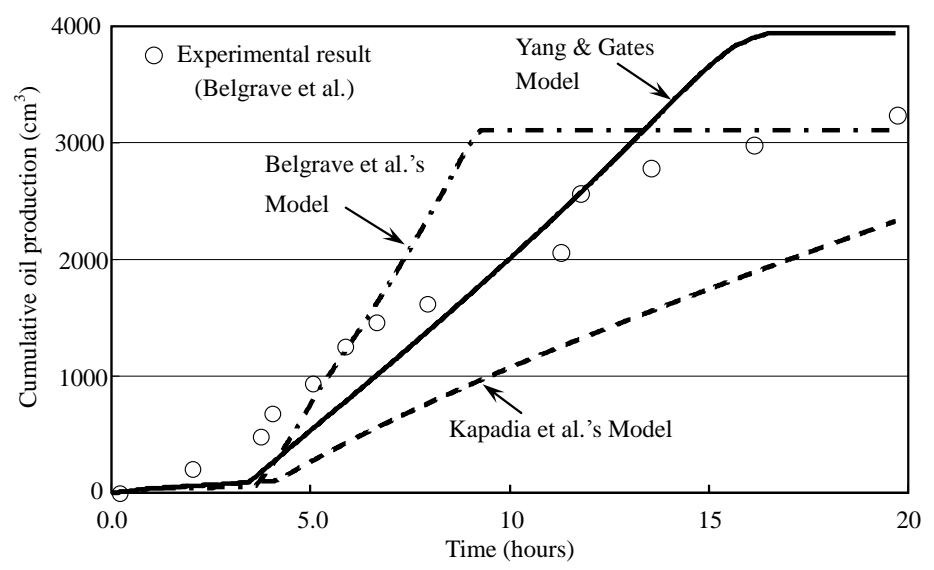

Figure5. Comparison between cumulative bitumen production of experiment and simulations

\subsection{Comparison of Chemical Reaction Modeling for Combustion Tube Test}

Figures 5 and 6 show comparisons of simulation results of cumulative oil production and temperature profiles, respectively, by three chemical models by Kapadia et al. ${ }^{[3]}$, Yang and Gates ${ }^{[5]}$ (Y-G model) and Belgrave et al. ${ }^{[8]}$ with comparing with the results of combustion tube-test ${ }^{[8]}$. Three block models shows obviously different simulation results, and the Y-G model shows better quantitative matching than other two models with the experiment. It is concluded the Y-G model has an advantage to simulate the bitumen combustion, especially combustion front propagation with the combustion tube test.

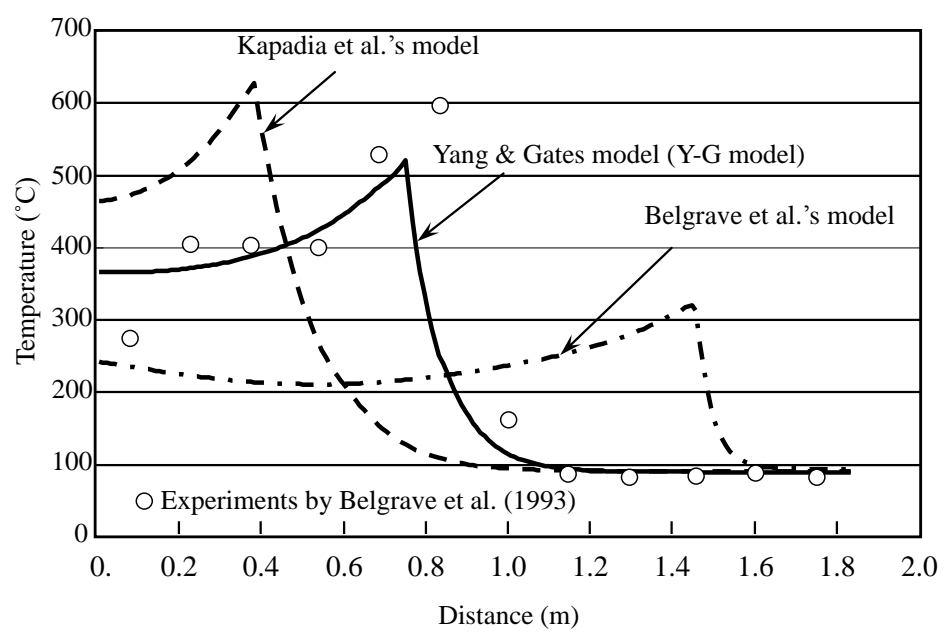

Figure6. Comparison between temperature profiles (at 7.92 hours from start of ignition) of experiment and simulations (3D model) by three models 


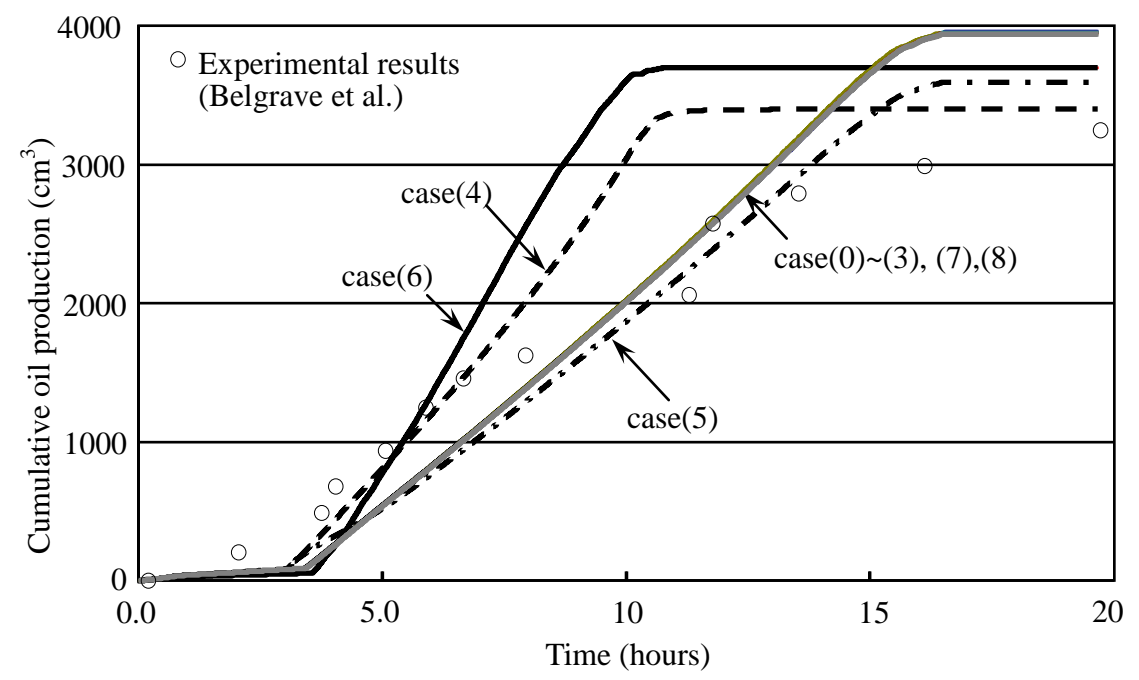

Figure7. Comparisons of cumulative oil production between four assumed cases

\subsection{Screening of Major Chemical Reactions}

The Y-G chemical model consists 8 chemical reactions showed the better matching results with experimental results than others. However, we had a question whether full 8 chemical reactions are necessary to express ISC process for bitumen or not. As the second stage of our simulation study, we have tried to screening of major chemical reactions to simplify and stabilize numerical calculations for field scale simulations on bitumen productions by ISC or THAI process from oil sands reservoirs, because ISC or THAI simulation for a 3D field scale reservoir with 8 chemical reactions was required much longer CPU processing time and larger hardware capacity than that of SAGD process.

The screening of chemical reactions were done by deleting a reaction one by one from the Y-G model consists 8 chemical reactions. Figure 7 shows the simulation results on cumulative oil production to show the roles of the reactions. The case (0) shows the basic result by calculating using all reactions of the Y-G model. Each case (1) to (8) shows the result by deleting each reaction (1) to (8) from the model, respectively. If the simulation shows much different result with that of the model, it can be judged that the deleted reaction has an important role in the simulation. As shown in Figure 7, the case (4), (5) and (6) are not consistent with case (0) using all reactions. It is clear that essential reactions affecting bitumen production behavior are LTO reactions (4) and (5) and HTO reaction (6).

In order to confirm whether numerical simulations using the reactions screened can reproduce the experiment. Figures 8 shows the simulation results of cumulative oil and gas production by using three chemical reactions with comparison to ones by original Y-G model. The simulations results using only three chemical reactions can reproduce almost same results by the model. Thus, bitumen production behavior occurred in the combustion tube experiment can be characterized by LTO reactions (4) and (5) and HTO reaction (6).

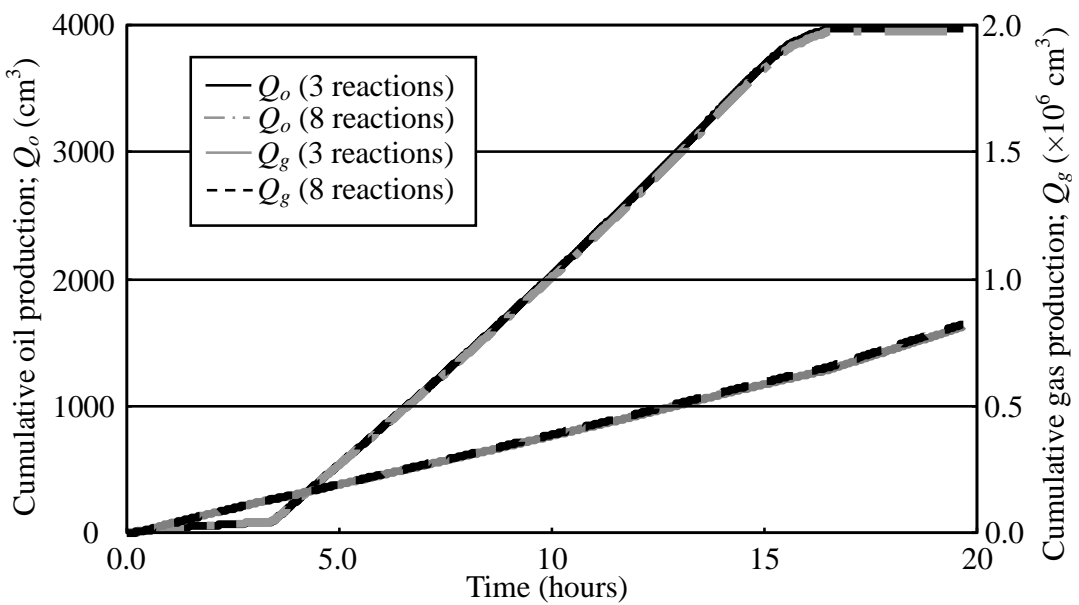

Figure8. Comparisons of cumulative oil, gas production between three and full eight chemical reactions presented by Yang and Gates (2009) 


\section{Modeling of thai Process}

The schematic concept of THAI process (Figure 1) uses a horizontal production well instead of a vertical production well (Xia et al. ${ }^{[7]}$ ). Firstly, air is injected to oil sands reservoir by using injection well located at the upper part of reservoir. In addition, bitumen is ignited with air injection at the same time. In the combustion zone generating heat, bitumen viscosity is decreased by the heat and its mobility is increased and bitumen moves down and is produced from a horizontal production well.

In conventional ISC process, gravity separation of gas and oil was occurred during moving to other vertical production well, because long distance between injection and production wells ${ }^{[6]}$. However, for the case of THAI process, this problem may not be occurred, because oil is drawn down into perforated section of the horizontal production well where just below the combustion zone ${ }^{[7]}$.

\section{Field SCale 3D Simulation}

\subsection{THAI Process}

Numerical simulations were conducted for bitumen production by THAI process from an homogeneous oil sands reservoir that has $500 \mathrm{~m}$ in length, $100 \mathrm{~m}$ in width and $25 \mathrm{~m}$ in thickness, respectively. The simulation conditions of the model are listed in Table 2.

3D numerical grid blocks model for THAI process is shown in Figure 9. The size of grid blocks in $x, y$ and $z$ directions were defined as $12.5 \mathrm{~m}, 11.1 \mathrm{~m}$ and $3.1 \mathrm{~m}$, respectively. In addition, one vertical injection well and one horizontal production well were set as described in Figure 1. The three chemical reactions screened from the Y-G model were used for the numerical simulation of THAI process. For initial 90 days, steam circulation in the production well was conducted to preheat oils sands around the producer. After that, air was injected from the injector and bitumen was ignited in the block with heating to $600{ }^{\circ} \mathrm{C}$.

Table2. Field scale simulation conditions for THAI

\begin{tabular}{|c|c|}
\hline Initial Temperature $\left({ }^{\circ} \mathrm{C}\right)$ & 12 \\
\hline Initial Pressure $(\mathrm{kPa})$ & 2600 \\
\hline Porosity & 0.34 \\
\hline Horizontal Permeability (md) & 6700 \\
\hline Vertical Permeability (md) & 1340 \\
\hline Initial Water Saturation & 0.40 \\
\hline Initial Oil Saturation & 0.60 \\
\hline Effective Formation Compressibility $\left(\mathrm{kPa}^{-1}\right)$ & $1.4 \times 10^{-5}$ \\
\hline Bitumen Mole Fraction (Maltenes) & 0.80 \\
\hline Bitumen Mole Fraction (Asphaltenes) & 0.20 \\
\hline Maximum Air Injection Rate $\left(\mathrm{m}^{3} / \mathrm{day}\right)$ & $1.0 \times 10^{5}$ \\
\hline Bottom Hole Pressure (Producer) $(\mathrm{kPa})$ & 2500 \\
\hline
\end{tabular}

Ref. Greaves (2011)

Figures 10 to 12 show temperature profile, coke concentration and oil saturation at the lower and left cross section after 365 days, respectively. The zone, where coke concentration was high, was formed ahead of the combustion zone. The zone with higher oil saturation than other regime was formed ahead of the coke zone.

The higher oil saturation zone was formed because oil of upper part of the reservoir flowed downward, and oil mobility was predicted higher in this zone. This is just consistent with THAI process characteristics with the coke zone created ahead of the combustion zone and the mobile oil zone created ahead of the coke zone as shown in Figure 1 (Xia and Greaves,2006) ${ }^{[11]}$. In addition, the break-through of air including $\mathrm{O}_{2}$ into the production well was not confirmed. 
Screening of Major Chemical Reactions in In-Situ Combustion Process for Bitumen Production from Oil Sands Reservoirs

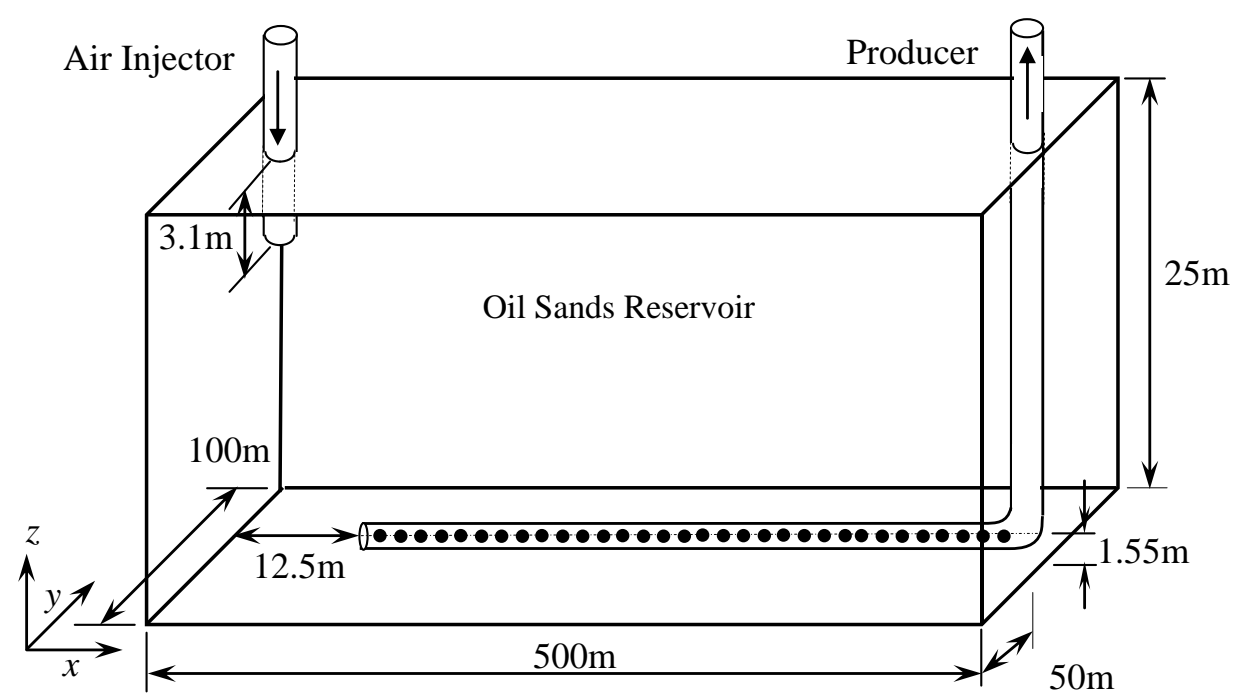

Figure9. Numerical simulation model for THAI process

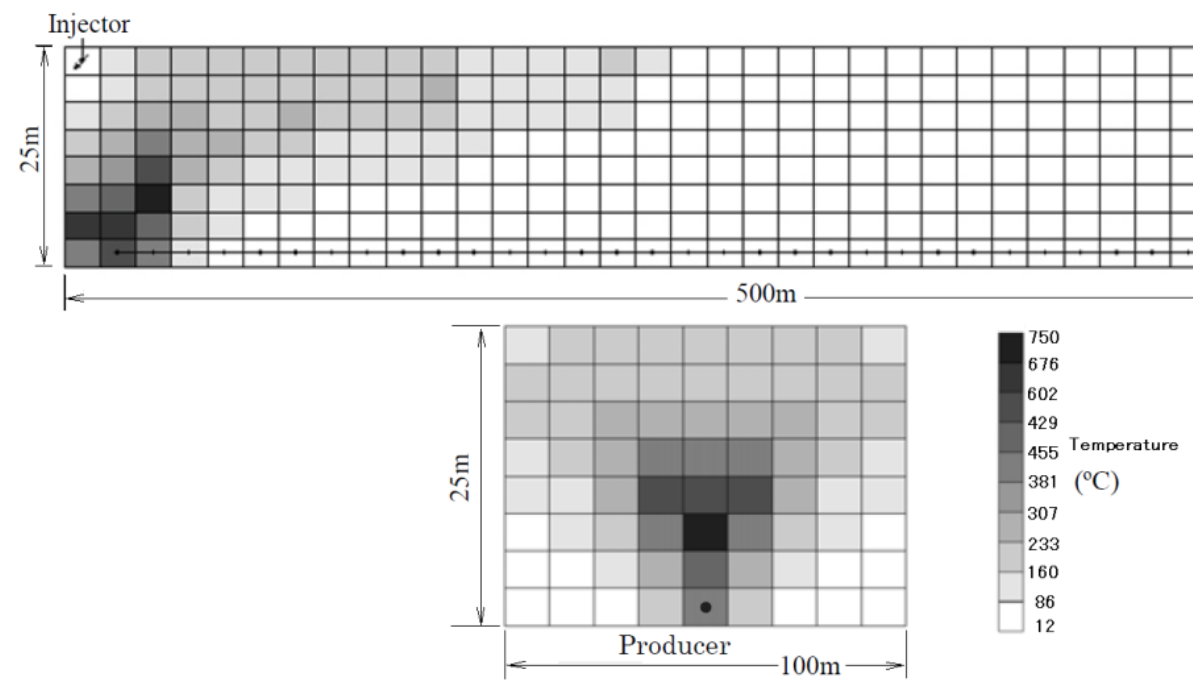

Figure10. Temperature profile after 365 days
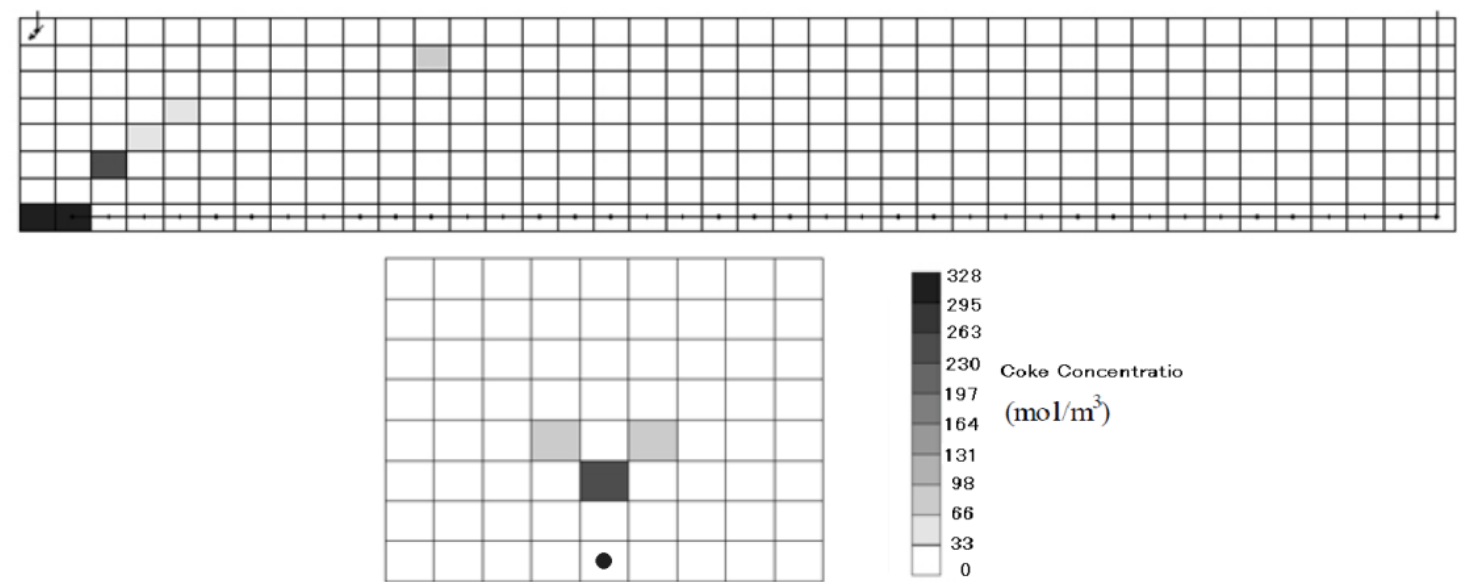

Figure11. Coke concentration after 365 days 

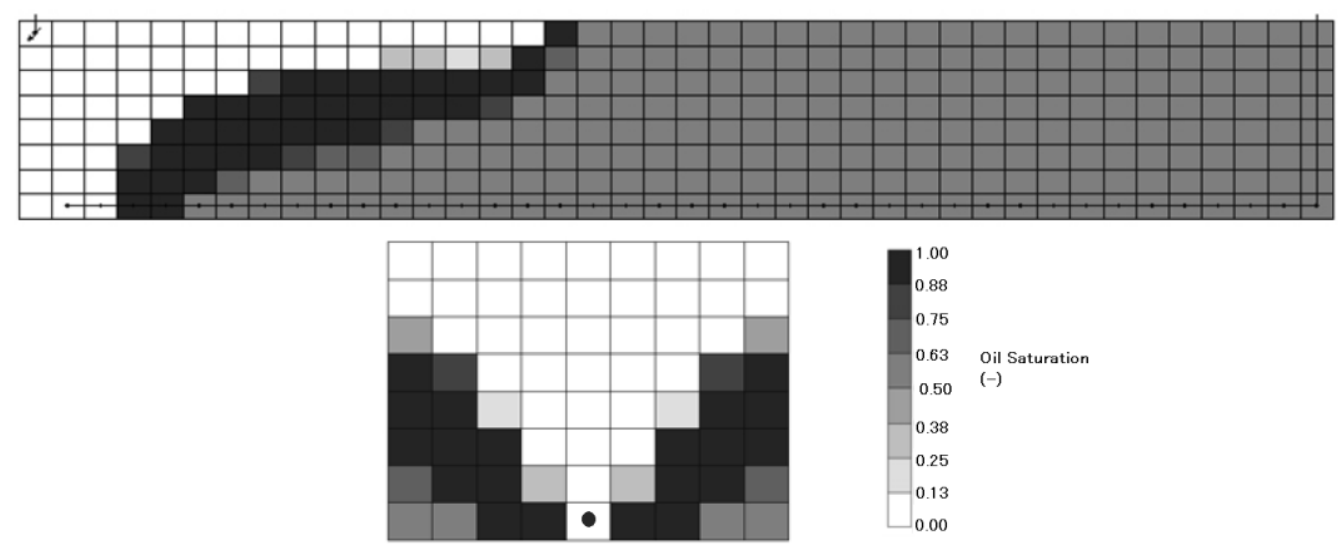

Figure12. Oil saturation after 365 days

\subsection{Comparison of THAI and SAGD Processes}

The production performance of THAI process was investigated by comparing simulation results on bitumen production rate with those by two steam injection methods, SAGD and Toe-to-Heel Steam Flooding (THSF) processes (Xia and Greaves, 2006) ${ }^{[11]}$. THSF process is similar to THAI process but THSF process injects steam instead of air. The numerical simulation model of THSF process was constructed with the same grid blocks model of THAI process (see Figure 9). During initial 90 days, steam circulation was conducted in the horizontal production well, and then steam injection started from injection well and fluids were produced from the horizontal well. On the other hand, the numerical simulation model for SAGD process is constructed. As shown in Figure 13, two horizontal wells were set with $5 \mathrm{~m}$ in vertical distance. During initial 90 days, steam circulation was conducted in the both horizontal wells, and then steam was injected from the upper well and fluids were produced from the lower well. Operation conditions for THSF process and SAGD process are listed in Table 3 (Kumasaka et al., 2016) ${ }^{[12]}$.

Figure 14 shows the simulation results of bitumen production rate, $q_{o}$, and cumulative oil production, $Q_{o}$, by three processes. Average bitumen production rate by THAI, THSF and SAGD process were 28, 70 and $94 \mathrm{~m}^{3} /$ day, respectively. Both of Oil production rate and cumulative oil production by THAI process were lower than that of other steam injection processes. In addition, oil recovery ratio after 6 years by three processes was $24.5,60.4$ and $81.9 \%$, respectively.
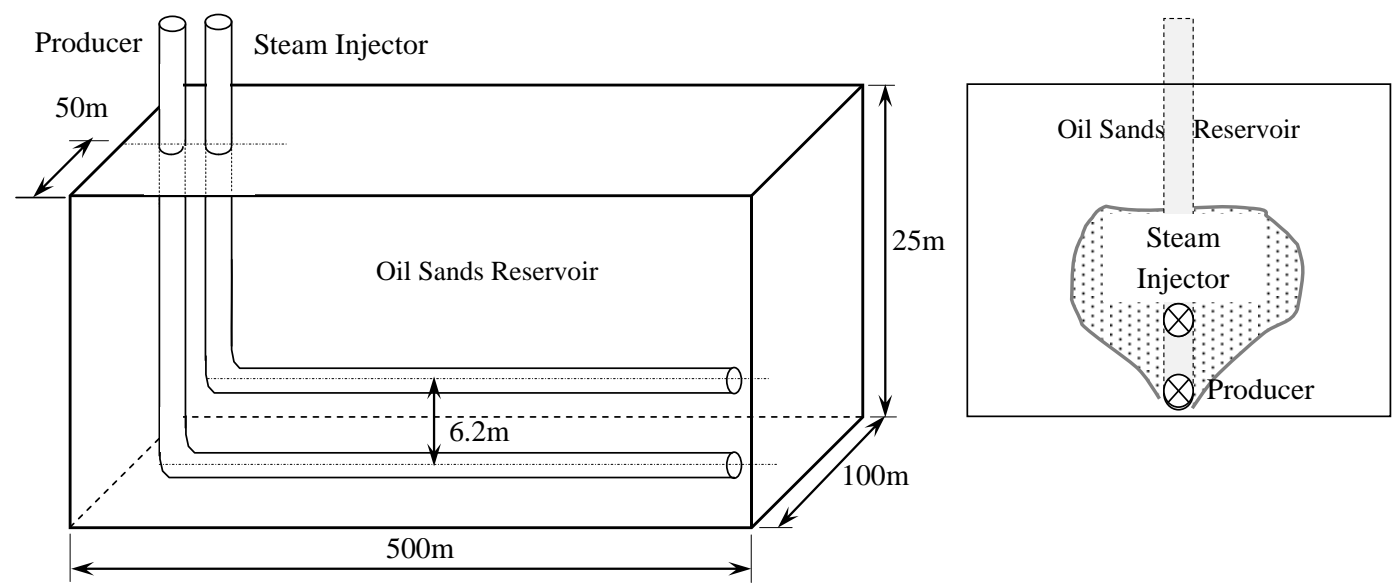

Figure13. Numerical simulation model of SAGD process (Kumasaka et al., 2016)

Table3. Conditions of SAGD and THSF processes

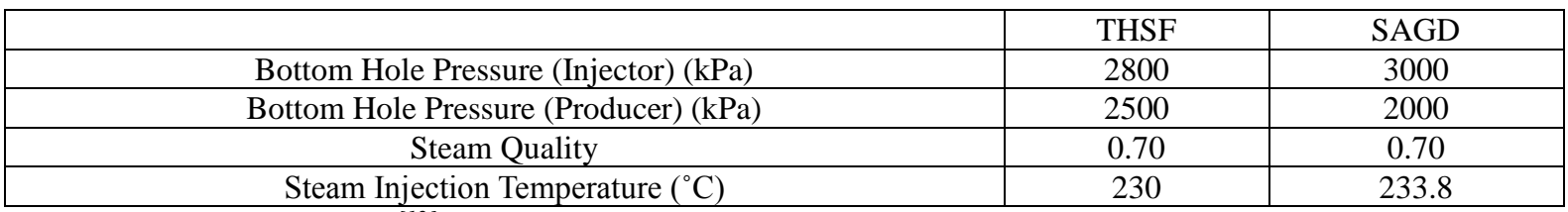

Ref. Kumasaka et al., 2016) ${ }^{[12]}$ 


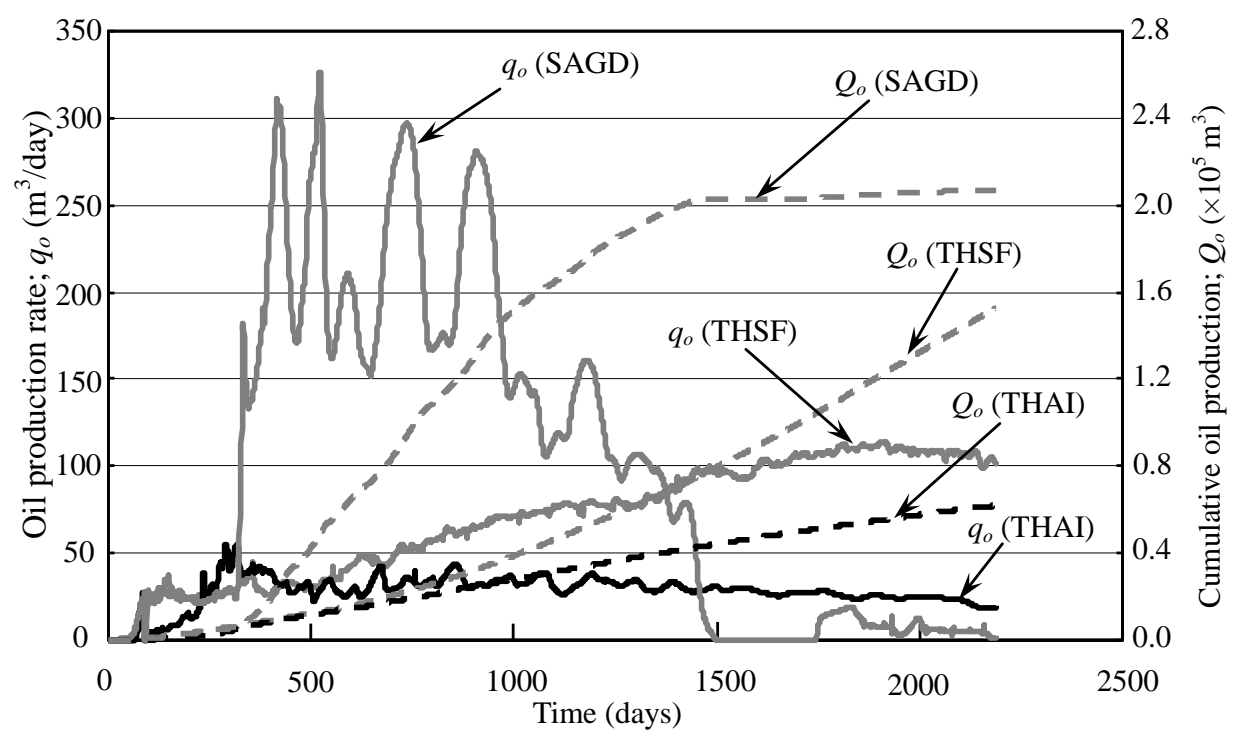

Figure14.Comparison of bitumen productions by THAI, SAGD and THSF processes

\section{CONCLUSions}

In this study, screening of chemical reactions used in numerical simulations has been done for in-situ combustion (ISC) process to produce bitumen from oil sands reservoir. The numerical simulations with the chemical reaction model presented by Yang and Gates (2009) (Y-G model) could show the good matching with the combustion tube experiment. In this study, just three major reactions (LTO reactions (4), (5) and HTO reaction (6)) were screened based on numerical simulations by extracting a reaction one by one from the Y-G model consists from eight chemical reactions.

The field scale 3D numerical simulation using the three reactions on THAI (Toe-to-Heel Air Injection) process, an expected ISC technology to produce bitumen, has been carried out successfully for a typical oil sands reservoir. According to the field scale numerical simulations of THAI process, the coke zone was formed ahead of the combustion zone and the mobile oil zone was formed ahead of the coke zone. The bitumen production characteristic of THAI process could be reproduced by the numerical simulation. The average oil production rate and oil recovery ratio during 6 years by THAI process were $28 \mathrm{~m}^{3} /$ day and $24.5 \%$, respectively. Furthermore, present numerical simulation results on bitumen production and oil recovery ratio by THAI process show 1/3 of that by SAGD process.

\section{ACKNOWLEDGEMENTS}

This work was partly supported by JAPEX Japan Petroleum Exploration Co., Ltd. (JAPEX).

\section{REFERENCES}

[1] Butler, R.M. and Stephens, D.J. (1981). The gravity drainage of steam-heated heavy oil to parallel horizontal wells, Journal of Canadian Petroleum Technology (JCPT), 20(2), 90-96.

[2] Sasaki, K., Akibayashi, S., Yazawa, N., Doan, Q. Farouq Ali, S.M. (2001). Experimental Modeling of the SAGD Process -Enhancing SAGD Performance with Periodic Stimulation of the Horizontal Producer, SPE Journal, 6 (1), 89-97.

[3] Kapadia, P. R., Kallos, S. M., Chris, L. Gates, I. D. (2011). Potential for hydrogen generation from in situ combustion of Athabasca bitumen, Fuel, 90, 2254-2265.

[4] Turta, A.T., Chattopadhyay, S.K., Bhattacharya, R. N., Condrachi, A., Hanson, W. (2007). Current Status of Commercial In Situ Combustion Projects Worldwide, Journal of Petroleum Technology, 46-11, 1-7.

[5] Yang, X., Gates, I. D. (2009). Combustion kinetics of Athabasca bitumen from 1D tube experiments, Natural Resources Res., 18(3), 193-211.

[6] Pfefferle, W.C. (2009). Method for in-situ combustion of in-place oils, US Patent 20090321073 A1.

[7] Xia, T. X., Greaves, M., Turta, A., Ayasse, C. (2003). THAI - a 'short-distance displacement' in situ combustion process for the recovery and upgrading of heavy oil, Trans IChemE, Part A, 81, 295-304.

[8] Belgrave, J. D. M., Moore, R. G., Ursenbach, M. G.., Bennion, D. W. (1993). A comprehensive approach to in situ combustion modeling, SPE Paper 20250. 
[9] Greaves, M. (2011). Upscaling THAI: Experiment to pilot, SPE Paper 148989-MS, https://doi.org/ 10. 2118/148989-MS, 1-19.

[10] Yang, M., Chen, Z., Haring, T. G.. (2016). An Improved Reaction Kinetics Model of In-Situ Combustion for Pre-Steamed Oil Sands, SPE Canada Heavy Oil Technical Conference (Calgary), SPE 180728-MS, $1-16$.

[11] Xia, T. X., Greaves, M. (2006). In situ upgrading of Athabasca tar sand bitumen using THAI, Trans IChemE, Part A, 84, 856-864.

[12] Kumasaka, J., Sasaki, K., Sugai, Y., Alade, O.S., Nakano, M. (2016). Measurement of viscosity alteration for emulsion and numerical simulation on bitumen production by SAGD considering in-situ emulsification, Journal of Earth Science and Engineering, 6(1), 10-17.

\section{AUTHORS' BIOGRAPHY}

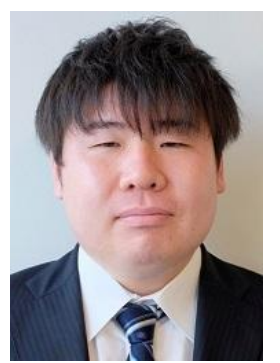

Yuta Yoshioka, has achieved BS and MS degrees in Earth Resources Engineering, Kyushu University, Japan. After the graduation in 2014, he joined Mitsubishi Corporation Exploration Co., Ltd. as a reservoir engineer, and recently he is conducting some studies to increase a value of a shale gas asset in Canada such as reserves evaluation and completion optimization.

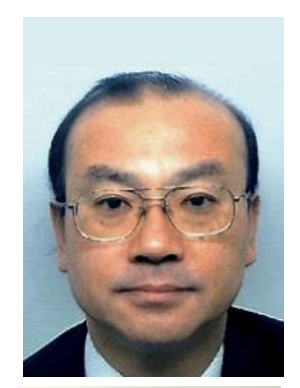

Kyuro Sasaki, is a professor of Department of Earth Resources Engineering, Faculty of Engineering, Kyushu University, Japan since 2005. He holds BS, MS and $\mathrm{PhD}$ degrees from Hokkaido University, Sapporo, Japan. His research interests are fluid mechanics and heat $\&$ mass transfer phenomena and production methods in Mining and Petroleum Industries.

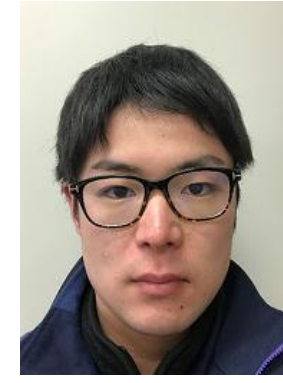

Kyoichi Takatsu, has achieved BS and MS degrees in Earth Resources Engineering, Kyushu University, Japan. After the graduation, he joined INPEX Corporation as a petroleum engineer from April, 2017.

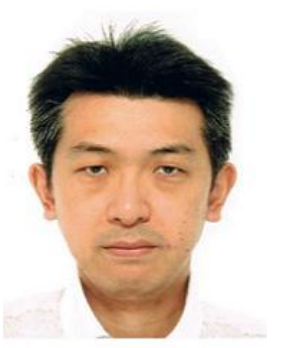

Yuichi Sugai, is an associate professor at Kyushu University. Previously, he was with the University more than 10 years. His research interests include experimental and numerical studies on EOR techniques, especially Microbial EOR. He holds $\mathrm{MS}$ and $\mathrm{PhD}$ degrees from Tohoku University.

Citation: Kyuro Sasaki et al, (2017). Screening of Major Chemical Reactions in In-Situ Combustion Process for Bitumen Production from Oil Sands Reservoirs, International Journal of Petroleum and Petrochemical Engineering (IJPPE), 3(4), pp.82-92, DOI: http://dx.doi.org/10.20431/2454-7980.0304008

Copyright: () 2017 Kyuro Sasaki et al. This is an open-access article distributed under the terms of the Creative Commons Attribution License, which permits unrestricted use, distribution, and reproduction in any medium, provided the original author and source are credited 